\title{
Conhecimentos de Acadêmicos de Educação Física sobre a Ginástica a partir da Percepção de Docentes do Ensino Superior
}

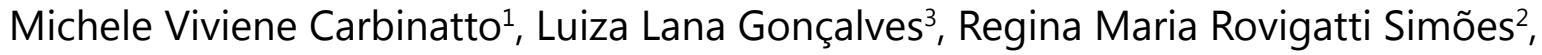 \\ Wagner Wey Moreira², Myrian Nunomura4, \\ ${ }^{1}$ Escola de Educação Física e Esporte da Universidade de São Paulo \\ 2Universidade Federal do Triângulo Mineiro \\ ${ }^{3}$ Universidade Federal de Mato Grosso do Sul \\ ${ }^{4}$ Escola de Educação Física e Esporte de Ribeirão Preto da Universidade de São Paulo \\ * Autora para correspondência: mcarbinatto@usp.br
}

\section{RESUMO}

O objetivo do presente estudo foi verificar, no discurso de catorze docentes que atuam nos cursos de licenciatura em Educação Física em universidades paulistas, o conhecimento prévio de ginástica dos alunos ingressantes no ensino superior e quais características devem ser apresentadas nessa disciplina nos referidos cursos. Após a realização de entrevistas, os dados foram avaliados pela Análise de Conteúdo, e, por meio deles, identificamos que todos os docentes apontaram os conhecimentos prévios como insuficientes e advindos da mídia televisiva, de academias de ginástica e circo, bem como notaram preconceitos em relação à modalidade. Quanto aos fundamentos necessários, os docentes indicaram a importância do reconhecimento dos fundamentos gerais, como elementos corporais, história, arbitragem, e, em minoria, de aspectos pedagógicos e metodológicos; a desmistificação dos preconceitos pelos estudos científicos e, por fim, tendências gerais da modalidade. É preciso que os fundamentos essenciais da ginástica sejam oferecidos aos discentes, sem perder de vista que devemos formar profissionais educadores e pesquisadores para um contexto plural e complexo.

Palavras-Chave: Ginástica; Ensino; Educação Superior; Instituições Acadêmicas.

\begin{abstract}
The aim of this study was to verify, in the speech of fourteen lecturers in undergraduate courses in Physical Education in São Paulo's universities, the prior gymnastics' knowledge of students entering in higher education and what features should be presented in this classes. After conducting interviews, data were analyzed by Content Analysis, in which we identified that all lecturers pointed out the previous knowledge as insufficient and coming from the television media, gyms and circus and noted prejudgement in relation to the gymnastics located as sport. As the necessary foundations, the interviewed indicated the importance in recognizing the general grounds such as physical elements, history, code of points and, in the minority, pedagogical and methodological aspects, demystification of bias by scientific studies and, finally, general trends of the sport. It is necessary that the essential fundamentals of gymnastics are offered to students and that we should educate professionals and researchers to a plural and complex context.
\end{abstract}

Keywords: Gymnastics; Teaching; High Education; Academic Institutions.

\section{Introdução ${ }^{1}$}

A atuação profissional na área de esportes é influenciada pela formação inicial, não formal (cursos, palestras...) e informal (relacionada à experiência). No que diz respeito à experiência, percebe-se que esta tem se tornado um dos principais fatores relacionados à prática pedagógica dos futuros profissionais (NELSON, CUSHION \& POTRAC, 2006).

No entanto, percebe-se que a experiência anterior dos alunos com o esporte, especificamente neste texto com a ginástica, tem influenciado na 
constituição de um ciclo vicioso, no qual a universidade reproduz o saber básico escolar relacionado com esse conteúdo e assim sucessivamente (BARBOSA-RINALDI \& SOUZA, 2003).

A fim de investigar a influência das experiências anteriores dos alunos na formação incial, este estudo buscou conhecer a opinião dos docentes de cursos de licenciatura em Educação Física, acerca do conhecimento prévio de seus alunos sobre a ginástica e também dos conhecimentos necessários à formação inicial nessa área.

Compreender o que os docentes percebem em relação ao ensino da ginástica faz com que possamos oportunizar uma reflexão acerca dos problemas que essa área de conhecimento enfrenta para sua materialização na escola e, assim, repensar os caminhos traçados pela ginástica na educação básica e formação inicial.

\section{Desenvolvimento}

Esta pesquisa, de cunho descritivo/exploratório, foi realizada com docentes universitários que atuam em cursos de Licenciatura em EF em universidades paulistas. De 165 cursos de Licenciatura em EF no estado de São Paulo (SP), chegamos a $29^{2}$ universidades e, dessas, a 24 que possuem em sua matriz disciplinas voltadas ao ensino da ginástica (após observação das ementas).

Em cada uma dessas universidades foi escolhido um docente que atendesse aos critérios de inclusão: atuar na instituição há pelo menos um ano; com dedicação mínima de vinte horas; como docente no ensino superior há pelo menos dois anos; com pelo menos uma disciplina relativa à ginástica representada pela Federação Internacional de Ginástica/FIG, a academias ou apenas que levasse sua denominação.

Após contatos e permissões, entrevistamos catorze docentes, seguindo os estudos de Bardin (2010) referentes à saturação de dados. A identificação dos docentes foi organizada pela letra $D$ e posteriormente um número por ordem de entrevistas feitas.

Para início dos procedimentos do método, gravou-se uma entrevista ${ }^{3}$ em áudio, com as seguintes questões geradoras: Qual o conhecimento sobre ginástica dos discentes ingressantes no curso de licenciatura? Qual/is conteúdo/s deve/m ser abarcado/s em uma disciplina sobre ginástica? Para o tratamento dos dados, optamos pela técnica de análise de conteúdo de Bardin (2010).

Os resultados indicam que, na percepção dos docentes, os conhecimentos sobre ginástica trazidos pelos acadêmicos eram poucos ou nulos, conforme pode ser observado na tabela 1.

Esses dados corroboram os obtidos em investigações desenvolvidas anteriormente, dentre elas as realizadas por Rinaldi-Barbosa e Souza (2003) com acadêmicos de Educação Física de Maringá e Campinas, que também evidenciaram a falta de experiência prévia com a ginástica.

A influência da mídia foi um fator apontado por vários docentes $(\mathrm{n}=6)$. Os alunos ingressantes no curso de licenciatura sofrem a interferência da mídia: esta, por vezes, expõe o esporte de for-

\begin{tabular}{|l|l|}
\hline A. Nulo ou Pouco & $\mathrm{D} 2, \mathrm{D} 4, \mathrm{D} 5, \mathrm{D} 8, \mathrm{D} 11, \mathrm{D} 12, \mathrm{D} 13, \mathrm{D} 14$ \\
\hline B. Mídia & $\mathrm{D} 2, \mathrm{D} 4, \mathrm{D} 6, \mathrm{D} 7, \mathrm{D} 10, \mathrm{D} 13$ \\
\hline C. Preconceitos & $\mathrm{D} 2, \mathrm{D} 6, \mathrm{D} 8, \mathrm{D} 12, \mathrm{D} 13$ \\
\hline D. Academia & $\mathrm{D} 8, \mathrm{D} 12, \mathrm{D} 13$ \\
\hline E. Circo & $\mathrm{D} 10$ \\
\hline
\end{tabular}

Tabela 1 - Categorias encontradas nos discursos sobre os conhecimentos de ginástica trazidos pelos alunos à Universidade. Fonte: Dados da pesquisa. 
ma espetacularizada, cria heróis que, ao mesmo tempo, podem motivar a iniciação na modalidade mas afrontar outros, especialmente em idade mais elevada, visto que as ginásticas competitivas apresentam média de idade na adolescência (NUNOMURA, PIRES \& CARRARA, 2009).

Os professores investigados revelaram a existência de preconceitos e equívocos quanto à prática de ginástica pelos universitários, muitos deles já discutidos em estudos anteriores, como em relação à estatura do praticante de Ginástica Artística (GA) (a pessoa fica com baixa estatura), tema abordado por Ferreira Filho, Nunomura e Tsukamoto (2006); a questão referente ao gênero (ginástica é para meninas), trabalhada por Antunes, Reis e Santos (2007); e, por fim, a noção de que a ginástica é altamente técnica, perigosa e pode causar lesões em quem a pratica, discutida no estudo de Nunomura, Carrara e Carbinatto (2009) sobre o desenvolvimento dos jovens e adolescentes na GA.

As experiências corporais relativas à ginástica pautaram-se nas ginásticas de academias - ginástica localizada, step, musculação $(\mathrm{n}=3)$ - e nas do circo $(n=1)$, que apresentam diversos elementos similares às modalidades competitivas. Observase que os alunos também possuem baixo conhecimento quanto às possibilidades de movimentos corporais, não apresentando, segundo a percepção dos docentes, domínio mínimo das capacidades físicas e das habilidades motoras.

Outro aspecto que foi destacado é o desconhecimento das manifestações de ginástica, já organizadas, consolidadas e sistematizadas por federações e organizações como a Federação Internacional de Ginástica (FIG).

Questionados os discentes que irão atuar na escola sobre quais conhecimentos devem apresentar, encontramos três categorias: 1) função da ginástica; 2) construção do conhecimento gímnico; e 3) conteúdos da área.

Em relação à função da ginástica, identificamos como seus papéis: transformar a vida das pessoas, formar a personalidade e melhorar o acervo motor. Dois docentes acreditam que, independente da modalidade de ginástica, a partir do momento em que a pessoa adquire o hábito saudável de praticá -la, isso transforma sua vida (D1; D8). A transformação da vida das pessoas também está ligada à formação da personalidade $(\mathrm{n}=2)$.

$\mathrm{E}$, por último, o fato de a ginástica apresentar posições corporais diferenciadas, bem como de trabalhar com a maioria das habilidades motoras e capacidades físicas, fez com que a sua função de melhorar o acervo motor também fosse destacada pelos docentes.

Já no que diz respeito à construção do conhecimento gímnico, percebemos, com base nos discursos, que ela está sobreposta ao que os alunos trazem sobre a modalidade - nulo ou muito pouco, e, por esse motivo, apresentá-la aos discentes torna-se o primeiro ponto da construção desse conhecimento (D2).

No Brasil, há carência de pesquisas na área da ginástica, especialmente daquelas apoiadas pela FIG (COELHO \& SIMOES, 2013), e podemos supor que isso se deva ao fato de o conhecimento apresentado nas universidades ainda estar no plano básico, no contato primário de reconhecimento das ginásticas e de seus fundamentos, mas deve apresentar reflexões e discussões aprofundadas, que suscitem produções diferentes e inovadoras.

Constatamos um conjunto de conteúdos da área que são abarcados pelos docentes, e que apresentaremos na tabela 2.

Os docentes $(n=10)$ destacam os elementos corporais como Fundamentos Gerais (A). Ressaltamos que a maioria deles apontou nomes de elementos, tais como rolamentos, estrelas, reversão, parada de mãos, mas não necessariamente, como fundamentos da modalidade.

Apenas um dos docentes revelou a preocupação em apresentar a lógica dos elementos aos alunos, para que eles compreendessem as sutilezas corporais da modalidade. Defendemos essa ideia, pois, ao entender os fundamentos, o aluno pode refletir melhor sobre os elementos que compõem as diferentes modalidades. Propostas como as de Leguet (1987), Russel e Kinsman (1986) e da própria Federação Internacional de Ginástica (RUSSEL, 2010) podem dar suporte ao docente para ampliar sua visão de ginástica. 


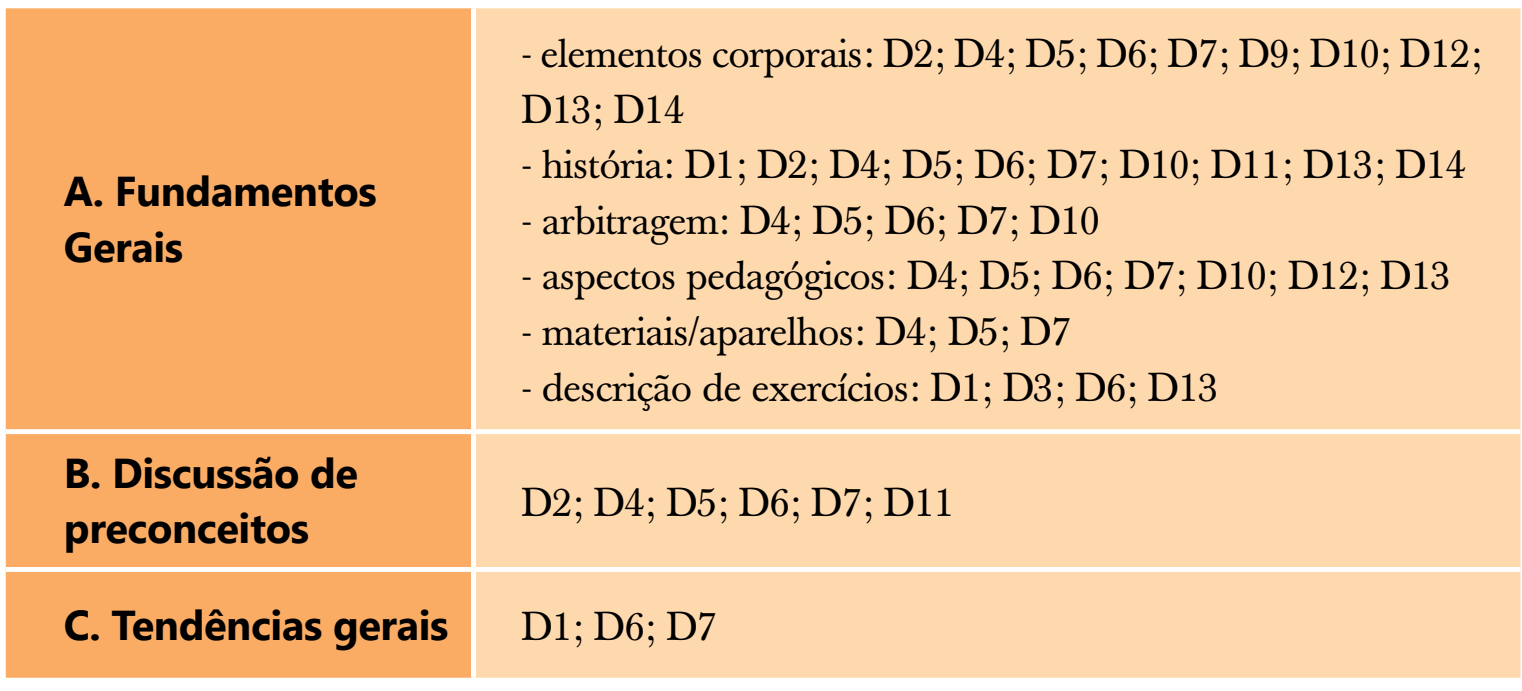

Tabela 2 - Conteúdos apontados como pertinentes, a serem trabalhados na Universidade no curso de Licenciatura. Fonte: Dados da pesquisa.

Percebemos neste ponto a preocupação dos docentes em suprir a carência dos alunos quanto aos conhecimentos básicos que deveriam ter sido ensinados na escola, tanto no que diz respeito ao desenvolvimento motor de forma geral, quanto aos movimentos específicos da ginástica.

Barbosa (1999) já nos alertava para este problema apontando que as disciplinas de ginástica em cursos superiores focavam a dimensão técnica do ensino, aprofundando pouco no quesito crítico e criativo do processo.

Figueiredo (2004) pondera que a relação do aluno com o saber na formação inicial em Educação Física se dá pelas experiências anteriores, ou até mesmo pela falta delas, o que estimula o desejo de vivência desses conteúdos. Além disso, afirma que os professores reproduzirão na escola suas experiências anteriores à graduação, ou seja, os alunos não tiveram experiência com a ginástica, tendo contato com a mesma somente em um ou dois semestres da graduação (PIZANI et al., 2015), o que não garante aproximação suficiente para que ele ministre esse conteúdo quando professor.

Quanto ao histórico da modalidade, importante conteúdo destacado no trabalho de Figueiredo e Hunger (2010): dez docentes apresentam em suas aulas as relações entre a história da ginástica e a área da Educação Física, os métodos ginásticos, a consolidação da modalidade específica (geralmente ginástica artística ou rítmica) e também ilustram tudo isso com filmes e/ou artigos dos ícones da modalidade (Nádia Comaneci, por exemplo).

Apenas três docentes ressaltaram a importância de os alunos compreenderem o núcleo primordial da ginástica e sua relação com a estética e a apresentação. Bezerra et al. (2014), em revisão sistemática sobre a ginástica na formação inicial, revelam que os docentes têm dificuldade em avançar no que é trazido pelos alunos da formação básica; assim, os conhecimentos técnicos, mecânicos com o enfoque competitivo (de posse dos docentes), são apenas repassados, e não discutidos nem ampliados na formação incial.

Apenas cinco docentes preocupam-se em apresentar a arbitragem para seus alunos. É importante destacar que quatro deles também recebem alunos do bacharelado e, portanto, dizem que, por esse motivo, é fundamental que compreendam a regra. A nosso ver, esse assunto não interessa apenas aos futuros bacharéis, mas a todos: ao conhecer sobre a regra da modalidade, melhor julgamos e criticamos a mesma.

Os aspectos pedagógicos $(\mathrm{n}=7)$ dizem respeito à compreensão de educativos e ajuda manual e segurança. Essas questões perpassam, também, a superação do aluno na própria aula da Universidade e o ganho de confiança para trabalhar na área.

Para os docentes D10 e D13, é preciso ter clareza de que o aluno deve aprender o processo 
pedagógico para saber ensinar e transmitir esse conhecimento aos seus futuros alunos e não somente executá-lo. Na literatura, a pertinência desse trabalho manual vive um paradoxo. Ao mesmo tempo que encontramos estudos que defendem tal prática (GERLING, 1998), outros salientam que, na iniciação, esse trabalho não deve ser enfatizado (RUSSEL, 2010).

Figueiredo (2004) afirma que a relação com o saber na formação inicial em Educação Física perpassa as experiências sociocorporais, enfatizando que, para os acadêmicos, o saber-fazer torna-se imprescindível para o conhecimento e o posterior ensino da área na educação básica. Parece-nos que com os docentes essa relação se estabelece da mesma forma, sendo a dimensão técnica supervalorizada no processo de ensino-aprendizagem.

Shiavon e Nista-Piccolo (2007) apontam a falta de conhecimento específico das modalidades gímnicas por parte dos professores, a dificuldade em estabelecer um método de trabalho e estratégias de ensino adequadas e, principalmente, a falta de estrutura material nas escolas como as causas para a ginástica não ser ensinada na educação básica. Ou seja, para romper com o ciclo vicioso da ginástica, referido por Barbosa-Rinaldi e Souza (2003), é necessário trabalhar tanto com as experiências do saber-fazer conforme imaginam os discentes, quanto com as dimensões pedagógicas e críticas do conteúdo, como deveriam fazer os docentes, ampliando as possibilidades de formação do professor crítico-reflexivo.

Os aspectos voltados aos materiais e aparelhos são citados por três docentes, sendo que dois deles apresentam a importância de "quebrar" a ideia de que só podemos praticar a ginástica se tivermos os aparelhos tradicionais. Os docentes D4 e D12 são os únicos que deixam clara a discussão sobre materiais aplicáveis, adaptáveis ou construídos para o ambiente da escola. Os demais se preocupam em apresentar os materiais para que os alunos identifiquem e compreendam as características básicas dos mesmos, mas não transcendem aos materiais oficiais.
O que não podemos tolerar são ações influenciadas pelos materiais, como a esclarecida pelo docente D1:

[...] no específico, de implementos de materiais, aí, sim, é que a diferença é gritante, principalmente na ginástica artística, porque há uma diferença na ginástica para homens e mulheres, em termos de aparelhos, em termos de postura, em termos de posição; então há, como eu trabalho com uma professora, com uma mulher, então a gente acaba, em determinado momento, dividindo as turmas: eu fico com os meninos, ela fica com as meninas, no sentido de utilização de aparelhos.

Observamos que os alunos não têm acesso a todo o conhecimento, e o docente impõe, na divisão conforme os sexos, o acesso a determinados conhecimentos da área.

Aprender a descrever os exercícios físicos é o foco dos conteúdos para quatro docentes, e eles ressaltam a importância de os discentes identificarem o posicionamento dos segmentos corporais, a musculatura que está sendo trabalhada e as articulações envolvidas, e que essa tarefa faz com que o discente aprenda a reconhecer posições corporais e terminologias da área.

Esse item corrobora diretamente um dos problemas enfrentados pelos docentes quanto à Discussão de Preconceitos (B) que os alunos têm sobre a ginástica quando ingressam na Universidade ( $\mathrm{n}$ =6). Num primeiro momento, são responsabilidades do docente mostrar que a ginástica é possível e apropriada a todos e aproximar os alunos em relação à área.

Os discursos veiculados na mídia também devem ser trabalhados em sala de aula, bem como as

[...] questões fisiológicas que envolvem a ginástica, principalmente os mitos, a questão da estatura; então, ele conhecer isso, os artigos, o que ele deve ler, quando vem "olha, minha filha quer fazer ginástica, mas eu acho que a ginástica vai deixar ela baixinha, né, vai prejudicar o crescimento dela, e aí, o que eu faço?". Então ele tem que tá prepa- 
rado pra isso, pra saber o que significa maturação biológica. (D7).

Aqui destacamos os estudos de Paiva (2001) e Ferreira Filho, Nunomura e Tsukamoto (2006), que mostram dados científicos da incompatibilidade dessa ideia. Ideias como a de que todo ginasta deve ser magro, com a busca pela definição muscular e pelo emagrecimento ou diminuição do percentual de gordura corporal, podem suscitar discussão sobre o poder midiático quanto à imagem corporal de atletas (LAVALLE \& ROBINSON, 2007; JEMMI et al., 2011) e levar a discussões interessantes como de casos de bulimia e anorexia na ginástica (JEMMI et al., 2011; BORTOLETO, BELLOTTO \& COSTA, 2007).

Os trabalhos sobre as separações sexistas nas modalidades ginásticas também são discutidos em estudos como o de Antunes, Reis e Santos (2007). Salientamos aqui, inclusive, que um dos professores citados não sabia que a Ginástica Rítmica já possui a participação de homem (com formato diferenciado) e, inclusive, há mais de dez anos se realiza campeonato mundial na modalidade.

Vale ressaltar que encontramos certo comodismo no docente D9 em relação à discussão de preconceito na área. Ele argumentou que procura disfarçar termos da ginástica, pois os mesmos estão imbricados de preconceitos. Nosso ponto de vista é o de que, ao invés de disfarçar, o docente pode argumentar, discutir e, justamente, mudar concepções impostas pela cultura e que se equivocam, entre as teorias da área.

Três docentes apresentam nas disciplinas o que eles consideram as Tendências Gerais $(\mathrm{C})$ da ginástica. $\mathrm{O}$ foco é voltado para os métodos de treinamento, a relação entre tecnologias e treinamento, as mudanças ocorridas em campeonatos mundiais e pan-americanos e, por fim, as novidades de aulas em academia.

\section{Conclusão}

Podemos perceber, por meio das pesquisas com as quais dialogamos neste texto, que os problemas relativos à legitimidade da ginástica na escola ou no ensino superior perpassam as questões de currículo, atuação profissional, políticas públicas educacionais, entre outras. No que diz respeito a esta pesquisa, notamos que dois problemas são eminentes: a dificuldade dos professores dos cursos de graduação em trabalhar com alunos que não tiveram experiências anteriores em ginástica; e a dificuldade de elencar conteúdos e práticas que subsidiem a formação ampla, que deem conta de preparar o professor para atuar na escola, rompendo com o ciclo citado no início deste texto.

Em nossa pesquisa afirmamos que os alunos possuem pouco conhecimento relacionado à ginástica quando chegam à universidade; e mais: que este advém da mídia, das academias ou do circo. Muitas vezes permeados de preconceitos no que diz respeito tanto à prática quanto aos sujeitos da ginástica. Os sujeitos desta pesquisa elencam como conhecimentos necessários a serem trabalhados no ensino superior aspectos relacionados à função da ginástica - transformação da vida, formação de personalidade e melhora do acervo motor; a construção do conhecimento gímnico e os conteúdos da área -, fundamentos gerais, discussão de preconceitos e tendências gerais, tais como métodos de treinamento, campeonatos mundiais e novidades das aulas de academia.

Em continuidade, percebemos que os docentes muitas vezes ministram suas disciplinas pautados numa dimensão técnica que é importante, mas não única, na formação profissional, sendo poucos aqueles que compreendem a necessidade de incluir os alunos na dimensão pedagógica da ginástica, discutindo com eles as possibilidades de aplicação, os mitos, preconceitos, medos que envolvem o saber ginástico.

A universidade é local de conhecimento contextualizado (ensino, pesquisa e extensão) e ampliado, aprofundando as discussões para além dos conhecimentos básicos que deveriam ser discutidos na escola. As aulas de ginástica nas Universidades devem propiciar a valorização da iniciativa e da autonomia, da criatividade e da invenção, a ação em relação ao discurso e a apropriação do saber 
em relação à sua transmissão, sem perder a sua especificidade: ensinar a ginástica.

\section{Notas}

1 Projeto desenvolvido com apoio do Conselho Nacional de Desenvolvimento Científico e Tecnológico (GNPq). Processo número: 472119/20141.

2 Dos 165 cursos de Educação Física - Licenciatura de São Paulo, 158 estão em funcionamento, e 54 estão presentes em Universidades; destes, alguns pertencem à mesma universidade, o que fez com que chegássemos a 29 cursos.

3 Entrevistas realizadas respeitando as diretrizes do Comitê de Ética em Pesquisa da Escola de Educação Física e Esporte da Universidade de São Paulo, aprovadas sob o registro CAAE: 01904112.1.0000.5391.

\section{Referências Bibliográficas}

ANTUNES, H. T.; REIS, B. B. \& SANTOS, F. C. P. "Preconceito aos Meninos na Prática da Ginástica Artística". Anais do I Seminário Internacional de Ginástica Artística e Rítmica de Competição, Rio de Janeiro, 2007, vol. 1, pp. 1-5.

BARBOSA, I. P. A Ginástica nos Cursos de Licenciatura em Educação Física do Estado do Paraná. 1999. 132f. Dissertação (Mestrado em Educação Física), Faculdade de Educação Física, Universidade Estadual de Campinas, 1999.

BARBOSA-RINALDI, I, P. \& SOUZA, E. P. M. de. "A Ginástica no Percurso Escolar dos Ingressantes dos Cursos de Licenciatura em Educação Física da Universidade Estadual de Maringá e Universidade de Campinas". Rev. Bras. de Cienc. do Esporte, Campinas, vol .24, n. 3, pp. 159-173, maio 2003.

BARDIN, L. Análise de Conteúdo. Lisboa: Edições 70, 2010.

BEZERRA, L. de A.; FARIAS, G. O.; FOLLE, A. \& BEZERRA, J. "Ginástica na Formação Inicial em Educação Física: Análise das Produções Científicas". Rev. Educ. Fís./UEM, vol. 25, n. 4, pp. 663-673, 2014.

BORTOLETO, M. A. G.; BELLOTTO, M. L. \& COSTA, G. E. A. "Estudos sobre a Nutrição Esportiva Aplicada à Ginástica Artística: Revisão de Literatura". Anais do I Seminário Internacional de Ginástica Artística e Rítmica de Competição, Rio de Janeiro, 2007, s/p.

COELHO, A. L.; SIMOES, R. M. R. Estado da Arte em Ginástica nos Periódicos da Educaşão Fúsica. 2013. Iniciação Científica. Universidade Federal do Triângulo Mineiro, Uberaba, 2013.

FERREIRA FILHO, R. A.; NUNOMURA, M. \& TSUKAMOTO, M. H. C. "Ginástica Artística e Estatura: Mitos e Verdades na Sociedade Brasileira". Rev.
Mackenzie Educ. Fís. Esporte, São Paulo, vol. 5, n. 2, pp. 21-31, 2006.

FIGUEIREDO, J. F. \& HUNGER, D. A. C. F. "A Relevância do Conhecimento Histórico das Ginásticas na Formação e Atuação Profissional de Educação Física”. Motriz, Rio Claro, vol. 16, n. 1, pp. 189-198, 2010.

FIGUEIREDO, Z. C. C. "A Formação Docente em Educação Física: Experiências Sociais e Relação com o Saber". Movimento, Porto Alegre, vol. 10, n. 1, pp. 89-111, jan.-abr. 2004.

GERLING, I. Teaching Children's Gymnastics: Spotting and Securing. New Jersey: Prentice Hall, 1998.

JEMMI, M.; SANDS, W. A.; SALMELA, J. H.; HOLVET, P. \& GATEVA, M. (editors). The Science of Gymnastics. New York: Routledge, 2011.

LAVALLE D. \& ROBINSON H. "In Pursuit of an Identity: a Qualitative Exploration of Retirement from Women's Artistic Gymnastics". Psychology of Sport and Exercise, vol. 8, pp. 199-141, 2007.

LEGUET, J. As Ações Motoras em Ginástica Desportiva. São Paulo: Manole, 1987.

NELSON, L. J.; CUSHION, C. J. \& POTRAC, P. "Formal, Nonformal and Informal Coach Learning: A Holistic Conceptualization". International fournal of Sports Science \& Coaching, vol. 1, n. 3, pp. 247-259, 2006.

NUNOMURA, M.; CARRARA, P. D. S. \& CARBINATTO, M. "Ginástica Artística Competitiva: Considerações sobre o Desenvolvimento dos Ginastas". Motriz, Rio Claro, vol. 15, n. 3, pp. 503-514, 2009.

; PIRES, F. R. \& CARRARA, P. "Análise do Treinamento na Ginástica Artística Brasileira". Rev Bras Cienc. Esporte, Campinas, vol. 31, pp. 25-40, 2009.

PAIVA, M. F. N. D. B. Avaliação Antropométrica: Estudos Comparativos do Crescimento de Crianças Praticantes e Não Praticantes de Ginástica Olimpica. 163f. Dissertação (Mestrado em Engenharia de Produção). Programa de Pósgraduação em Engenharia de Produção, Universidade Federal de Santa Catarina, Florianópolis (SC), 2001.

PIZANI, J.; ARAÚJO, M. A. de.; BRAGUIM, C.; BARBOSA-RINALDI, I. P. \& LOURENÇO, M. R. A. "As Disciplinas Gímnicas nos Cursos de Licenciatura em Educação Física do Estado do Paraná". Conexões, Campinas, vol. 13, n. especial, pp. 58-76, maio 2015.

RUSSELL, K. Fundamentos da Ginástica e da Literacia Motora. Lisboa: Federação de Ginástica de Portugal, 2010.

RUSSEL, K.; KINSMAN, T. Coaching Certification Manual. Level 1. Introductory gymnastics. Ontario: Gymnastics Canada Gymnastique Publication, 1986.

SCHIAVON, L. M. \& NISTA-PICCOLO, V. L. "A Ginástica vai à Escola". Movimento, Porto Alegre, vol. 13, n. 3, pp. 131-150, set.-dez. 2007.

Publicado em 22/12/2017. 